\title{
Central Obesity
}

National Cancer Institute

\section{Source}

National Cancer Institute. Central Obesity. NCI Thesaurus. Code C120381.

Obesity in which excess fat is accumulated primarily in the area of the abdomen. 